DOI: https://doi.org/10.24127/ajpm.v9i2.2800

\title{
ANALISIS SELF-CONFIDENCE DAN HASIL BELAJAR MATEMATIKA SMA DALAM KURIKULUM BERBASIS UNIT KEGIATAN BELAJAR MANDIRI
}

\author{
Agustin Nilasari ${ }^{1}$, Moh. Mahfud Effendi ${ }^{2^{*}}$, Octavina Rizky Utami Putri ${ }^{3}$ \\ 1,2*,3 Universitas Muhammadiyah Malang, Malang, Indonesia \\ *Corresponding author. Jl. Raya Tlogomas No. 246, 65144, Malang, Indonesia. \\ E-mail: $\quad$ agustinns027@gmail.com ${ }^{1)}$ \\ mahfud@umm.ac.id $^{2 *}$ \\ octavina@umm.ac.id ${ }^{3)}$
}

Received 06 May 2020; Received in revised form 17 June 2020; Accepted 29 June 2020

\begin{abstract}
Abstrak
Penelitian ini bertujuan untuk menganalisis self-confidence dan hasil belajar matematika siswa SMA dalam implementasi kurikulum berbasis UKBM. Untuk memperoleh data tentang self-confidence, menggunakan angket dan wawancara. Angket diberikan pada siswa SMA Negeri 8 Malang kelas XI dan XII IPA. Untuk keabsahan data, dilakukan wawancara baik terhadap guru maupun siswa. Sedangkan untuk memperoleh data tentang hasil belajar, maka menggunakan dokumen UAS Semester Ganjil 2019/2020. Analisis tingkat self-confidence menggunakan skala interval dengan kategori rendah, sedang, tinggi, dan sangat tinggi. Untuk menentukan rating scale, menggunakan persentase dan dikonfirmasi dengan kategori. Sedangkan tingkat hasil belajar menggunakan kategori yang sama dengan skala interval Kemendikbud. Berdasarkan analisis kualitatif didapat bahwa self-confidence siswa SMA dalam pembelajaran matematika berbasis UKBM tergolong tinggi, dan hasil belajarnya juga tinggi. Secara individual maupun klasikal, ada hubungan positif antara self-confidence dan hasil belajar. Oleh karena itu pembelajaran matematika berbasis UKBM perlu dikembangkan dan diterapkan di berbagai jenis dan jenjang sekolah.
\end{abstract}

Kata kunci: Self-confidence; hasil belajar; UKBM.

\begin{abstract}
The purpose of this study is to analyze the self-confidence and mathematics learning outcomes of high school in implementing the UKBM (independent learning unit)-based curriculum. To obtain data about self-confidence, use questionnaires and interviews. Questionnaire was given to students of SMA Negeri 8 Malang of class XI science and XII science. For data validity, interviews were conducted with both teachers and students. Meanwhile, to obtain data about learning outcomes, then using final exams documents in 2019/2020. The level of self-confidence analysis uses interval scales in the low, medium, high, and very high categories. To determine the rating scale, use percentages and confirm with categories. Whereas the level of learning outcomes uses the same category, and with an interval scale from the Ministry of Education and Culture. Based on qualitative analysis, it was found that high school students' self-confidence in learning mathematics based on UKBM was high, and the learning outcomes were also high. Individually and classically, there is a positive relationship between self-confidence and learning outcomes. Therefore, learning mathematics based on UKBM needs to be developed and applied in various types and levels of schools.
\end{abstract}

Keywords: Learning outcomes; self-confidence; UKBM.

\section{PENDAHULUAN}

Kurikulum merupakan seperangkat rencana yang harus diimplementasikan dalam bentuk pembelajaran (Effendi, 2019). Agar tujuan kurikulum dapat tercapai secara efektif dan efisien, maka pembelajaran harus menantang, menumbuhkan kemandirian, dan selfconfidence (Indonesia, 2013). Tujuan Standar Nasional Pendidikan 2013 adalah memperbaiki kualitas pembelajaran dengan melibatkan siswa (Ratulangi \& Arsyad, 
2016), pelibatan ini dapat meningkatkan self-confidence siswa. Self-confidence menjadi penting, karena kesuksesan dalam proses belajar dapat dipengaruhi oleh selfconfidence (Vandini, 2016).

Belajar matematika sebenarnya belajar self-confidence. Belajar matematika adalah membentuk pola pikir, berfikir kritis, rasional, dan objektif, dimana aspekaspek ini merupakan indikator selfconfidence (Nurkholifah, Toheri, \& Winarso, 2018). Sehingga sulit tidaknya siswa belajar matematika tergantung dari tingkat self-confidence-nya (Nurafni \& Pujiastuti, 2019). Siswa yang selfconfidence tinggi dapat meningkatkan hasil belajarnya (Wulandari \& Sinambela, 2017; Novitasari, 2016). Self-confidence membantu siswa mampu mengerjakan, menyelesaikan, dan mendapatkan hasil belajar yang memuaskan (Hendriana, 2014). Oleh karena itu, dalam pembelajaran matematika, self-confidence merupakan unsur wajib yang harus dimiliki siswa (Santosa, 2018).

Secara umum, self-confidence siswa Indonesia masih tergolong rendah. Di Tahun 2012 menunjukkan bahwa selfconfidence sekitar $13 \%$ dalam skala internasional (Isroila, Munawaroh, Rosidi, \& Muharrami, 2018), dan pada Tahun 2015, Indonesia berada pada peringkat 42 dari 49 negara. Oleh karena itu, kemampuan matematika dan sain siswa Indonesia berada pada level bawah dalam perankingan TIMSS dan PISA. Dari beberapa penelitian dinyatakan bahwa ada hubungan yang signifikan antara selfconfidence dengan hasil belajar (Relita \& Regina, 2015). Hubungan antara tingkat self-confidence dan hasil belajar ini sebesar 0,743 (Apollo, 2018). Bahkan hubungan keeratan antara self-confidence dengan hasil belajar sebesar 0,970 (Syam \& Amri, 2017). Semakin tinggi self-confidence siswa maka semakin tinggi juga hasil belajarnya (Astuti, Kurniasih, \& Nugraheni, 2016).

Self-confidence dapat tumbuh dan berkembang dengan baik jika lingkungannya mendukung dan memfasilitasinya (Apriliarini, 2015). Artinya, kurikulum dan pembelajaran di sekolah harus didesain agar self-confidence dapat tumbuh dan berkembang. Pembelajaran berbasis UKBM merupakan sebuah perangkat pembelajaran bagi siswa untuk mencapai kompetensi secara mandiri dengan menggunakan sistem kredit semester (Irwantha, Ayu Putu Sriasih, \& Nurjaya, 2017). Oleh karena itu, diharapkan melalui UKBM ini dapat membantu siswa secara mandiri dalam meningkatkan selfconfidence dan ketuntasan belajarnya. Kegiatan mandiri tanpa didukung oleh selfconfidence maka tidak akan berjalan dengan baik. Pembelajaran berbasis UKBM menyaratkan siswa lebih aktif, kritis, inovatif, kreatif, bekerjasama, dan berkolaborasi, agar mempunyai selfconfidence yang tinggi sehingga bisa eksis di jaman milenial (Direktorat Pembinaan Sekolah Menengah Atas, 2017).

Pembelajaran matematika berbasis UKBM diterapkan pada 126 SMA di Malang. Buku UKBM yang digunakan diterbitkan oleh Musyawarah Guru Mata Pelajaran (MGMP) Matematika Kota Malang. Penerapan pembelajaran ini sudah berlangsung lebih dari 2 tahun. Ada beberapa sekolah dan guru yang tidak lagi mempergunakan UKBM, karena dianggap tidak efektif dan tidak efisien dalam pencapaian tujuan pembelajaran. Bahkan ada guru yang mengatakan, menggunakan UKBM atau tidak, sama saja. Sikap dan pernyataan tersebut muncul, karena selama ini memang belum ada evaluasi dan penelitian tentang pembelajaran matematika berbasis UKBM khususnya terkait dengan self-confidence dan hasil belajar.

Berdasarkan uraian di atas, maka tujuan penelitian ini untuk menganalisis bagaimana self-confidence dan hasil belajar siswa SMA dalam pembelajaran matematika berbasis UKBM.

\section{METODE PENELITIAN}

Analisis self-confidence dan hasil belajar pada masalah di atas adalah analisis kualitatif tentang tingkat self-confidence, dan hasil belajar matematika, serta hubungan keduanya sebagai dampak dari pembelajaran matematika berbasis UKBM. Indikator self-confidence meliputi percaya 
DOI: https://doi.org/10.24127/ajpm.v9i2.2800

pada kemampuan sendiri, tidak cemas dan mandiri dalam mengambil keputusan, memiliki konsep diri yang positif, hangat dan sopan dalam berinteraksi, serta berani menyampaikan pendapat (Syam \& Amri, 2017). Sedangkan hasil belajar adalah kemampuan siswa dalam menjawab soal Ujian Akhir Semester (UAS), yang dinyatakan dalam bentuk skor.

Untuk memperoleh data tentang selfconfidence, menggunakan instrument penelitian berupa angket dan wawancara. Angket diberikan pada siswa SMA Negeri 8 Malang kelas XI IPA sebanyak 6 kelas dan XII IPA sebanyak 2 kelas, rata-rata jumlah siswa perkelas sebanyak 35 siswa. Selanjutnya untuk mengetahui keabsahan data hasil angket ini, dilakukan cross cek melalui wawancara terhadap guru dan siswa yang mewakili kelas yang ditentukan secara acak. Sedangkan untuk memperoleh data tentang hasil belajar siswa, maka menggunakan dokumen UAS Semester Ganjil 2019/2020.

Analisis tingkat self-confidence menggunakan skala interval dengan kategori mulai dari rendah (R), sedang (S), tinggi (T), sampai sangat tinggi (ST), dengan pembobotan berturut-turut adalah: 1, 2, 3, dan 4 (Gay, L.R, et.al, 2006; McMillan, JH., 2008). Untuk menentukan rating scale, menggunakan persentase, dengan dikategorikan menjadi empat, yaitu rendah $(\mathrm{R})$, sedang $(\mathrm{S})$, tinggi $(\mathrm{T})$, dan sangat tinggi (ST) dengan interval berturutturut $0-<25 ; 25-<50 ; 50-<75$; dan 75 - 100. Tingkat kemampuan siswa juga dikategorikan menjadi empat yaitu rendah $(\mathrm{R})$, sedang $(\mathrm{S})$, tinggi $(\mathrm{T})$, dan sangat tinggi (ST) dengan interval berturutturut adalah: $0-<60 ; 60-<$ $74 ; 74-<88 ; \quad$ dan $\quad 88-100$ (Kemendikbud, 2017).

\section{HASIL DAN PEMBAHASAN}

Tujuan utama pembelajaran berbasis UKBM adalah memberi stimulus belajar untuk menumbuhkan kemandirian dan keterlibatan siswa secara aktif dalam penguasaan kompetensi (Direktorat Pembinaan Sekolah Menengah Atas, 2017;
Hermawan, F., 2019). Proses belajar berbasis UKBM akan menumbuhkan sikap kemandirian dan self-confidence siswa karena harus terlibat aktif secara individual dalam penguasaan kompetensi (Hendriana, H., 2014; Pratiwi, ID.,\&Laksmiwati, H., 2016).

Secara umum self-confidence siswa SMAN 8 Malang dalam pembelajaran berbasis UKBM (Tabel 1), tergolong tinggi (T), tidak ada yang masuk kategori rendah (R) dan sedang (S). Jika dikelompokan akan menjadi dua kelompok yang sama besar yaitu kategori tinggi (T) dan sangat tinggi (ST). Prilaku berinteraksi merupakan indikator self-confidence yang sangat tinggi (ST), dibanding dengan indikator lainnya. Tetapi jika dilihat dari skornya, percaya pada kemampuan dirinya sendiri memiliki skor paling rendah. Hal ini harus diperhatikan, karena kepercayaan pada diri sendiri ini akan mempengaruhi kecemasan dalam melakukan suatu tindakan, sehingga tidak berani dalam menyampaikan pendapat, dan bahkan konsep dirinya menjadi rendah (Hendriana, 2014).

Tabel 1. Indikator dan kategori (KG) Selfconfidence (SC).

\begin{tabular}{llcc}
\hline No & Indikator & Skor & KG \\
\hline 1. & $\begin{array}{l}\text { Memiliki konsep diri } \\
\text { Berani menyampaikan } \\
\text { pendapat }\end{array}$ & 50,2 & $\mathrm{~T}$ \\
3. & $\begin{array}{l}\text { Tidak cemas melakukan } \\
\text { tindakan }\end{array}$ & 55,7 & $\mathrm{~T}$ \\
4. & $\begin{array}{l}\text { Percaya pada kemampuan } \\
\text { sendiri }\end{array}$ & 54,0 & $\mathrm{~T}$ \\
5. & $\begin{array}{l}\text { Hangat dan sopan } \\
\text { berinteraksi }\end{array}$ & 86,3 & $\mathrm{ST}$ \\
6. $\begin{array}{l}\text { Mandiri dalam mengambil } \\
\text { keputusan }\end{array}$ & 71,7 & $\mathrm{~T}$ \\
Rerata & 60,6 & $\mathrm{~T}$ \\
\hline
\end{tabular}

Percaya pada kemampuan sendiri menjadi sangat penting yang harus ditumbuhkan dan ditingkatkan. Siswa lebih senang ditunjuk guru untuk menjelaskan materi didepan kelas, dan kadang tidak mau maju dan tidak berani tampil di depan kelas, karena merasa orang lain lebih mampu. Hal yang menjadi penyebab indikator percaya diri mendapat skor paling rendah. Faktor lain yang mempengaruhi siswa tidak berani 
DOI: https://doi.org/10.24127/ajpm.v9i2.2800

tampil adalah tidak memahami materi, belum siap, dan tidak konsentrasi dalam pembelajaran karena pengaruh eksternal (Setiyorini, 2016). Konsentrasi belajar juga dipengaruhi oleh kondisi lingkungan belajar, metode, atau model pembelajaran yang digunakan (Setyani \& Ismah, 2018).

Kehangatan dan sopan dalam berinteraksi baik di dalam maupun di luar pembelajaran, bergaul dengan temanteman, aktif dalam kegiatan ekstrakulikuler, dan sejenisnya, merupakan bentuk pemahaman siswa terhadap arti kehidupan dan sekitarnya. Heris (2014) menjelaskan bahwa siswa yang memiliki rasa selfconfidence dapat berusaha lebih baik menghargai orang lain dan tidak mudah menyalahkan orang lain, karena siswa memiliki keyakinan bahwa setiap orang memiliki kemampuan untuk mengembangkan dirinya. Hal tersebut akan berpengaruh pada hasil belajar. Karena hasil belajar merupakan perubahan dalam hal kebaikan seperti halnya pengetahuan, sikap, serta keterampilan siswa setelah terjadinya proses pembelajaran (Komari Pratiwi, 2015).

Hal tersebut terbukti, dari hasil analisis terhadap lembar jawaban UAS siswa SMA Negeri 8 Malang kelas XI IPA dan XII IPA pada semester Ganjil 2019/2020, bahwa tingkat hasil belajarnya adalah sangat tinggi (ST), bahkan persentase hasil belajar siswa yang mendapatkan kategori Sangat Tinggi (ST) dan Tinggi (T) mencapai lebih dari 50\% (Tabel 2)

Tabel 2. Kriteria (KR) hasil belajar (HB).

\begin{tabular}{cc}
\hline KR & HB $(\boldsymbol{\%})$ \\
\hline ST & 50 \\
T & 16.66 \\
S & 16.66 \\
R & 16.66 \\
\hline
\end{tabular}

Berdasarkan Tabel 3 maka dapat dikatakan terdapat hubungan yang positif antara self-confidence dengan hasil belajar, artinya semakin baik tingkat self-confidence maka tingkat pemahaman semakin baik pula (Astuti et al., 2016). Hubungan antara self-confidence dengan hasil belajar dapat dianalisis secara individual. Hasil belajar dan self-confidence siswa, terlihat dengan jelas bahwa terdapat hubungan antara selfconfidence dengan hasil belajar. Ada kecendrungan bahwa self-confidence tinggi bersesuaian secara positif dengan hasil belajarnya.

Tabel 3. Kategori (KG) self-confidence $(S C)$ dan hasil belajar (HB).

\begin{tabular}{ccccc}
\hline \multirow{2}{*}{ KG $\boldsymbol{S C}$} & \multicolumn{4}{c}{ KG HB $(\%)$} \\
\cline { 2 - 5 } & $\mathbf{S T}$ & $\mathbf{T}$ & $\mathbf{S}$ & $\mathbf{R}$ \\
\hline ST & 33,3 & 0 & 8,3 & 8,3 \\
T & 16,7 & 16,7 & 8,3 & 8,3 \\
S & 0 & 0 & 0 & 0 \\
R & 0 & 0 & 0 & 0 \\
\hline
\end{tabular}

Hubungan self-confidence dan hasil belajar dalam pembelajaran berbasis UKBM sudah nampak jelas, padahal pelaksanaan pembelajaran matematika di SMAN 8 Malang belum berjalan dengan semestinya (Majid \& Linuwih, 2019). Selain dokumen UKBM belum menampakan materi dan kegiatan yang mencerminkan kemandirian, dan buku pendukung lainnya juga belum memadai. Secara umum, siswa tidak terbiasa dan belum siap untuk belajar mandiri, siswa yang pandai atau sudah selesai mempelajari dan memahami materi tertentu, biasanya menunggu temannya yang belum selesai.

Pada awal pelaksanaannya, banyak siswa mengeluh, mereka merasa kesulitan jika harus mengerjakan soal secara mandiri, apalagi penjelasan guru yang sangat sedikit. Pembelajaran menggunakan UKBM semestinya memiliki banyak kelebihan, jika faktor pendukung dipenuhi, dan guru mampu berfungsi sebagai fasilitator (Majid \& Linuwih, 2019; Wiharni, Amin, \& Lestari, 2018). Karena banyak faktor penyebab itulah, maka self-confidence dan hasil belajar siswa tidak optimal (Andayani \& Amir, 2019).

Sesuai hasil penelitian sebelumnya yang menjelaskan bahwa semakin besar self-confidence yang dimiliki siswa, maka akan berpenggaruh juga kepada hasil 
DOI: https://doi.org/10.24127/ajpm.v9i2.2800

belajarnya. Siswa yang self-confidence tinggi dapat meningkatkan hasil belajarnya (Wulandari \& Sinambela, 2017). Belajar matematika memerlukan dan menuntun siswa untuk berfikir kritis, rasional, serta objektik, dimana semua aspek tersebut merupakan indikator dari self-confidence (Nurkholifah et al., 2018). Anggapan sulit atau tidak sulinya matematika bergantung terhadap tingkat self-confidence (Nurafni \& Pujiastuti, 2019). Pada penelitian ini juga membenarkan teori tersebut, terlebih lagi pada pembelajaran berbasis UKBM siswa dituntut untuk berpikir kritis serta lebih bertindak kreatif dalam pembelajaran, jika siswa tidak memiliki self-confidence yang tinggi, maka juga akan sangat berpengaruh terhadap hasil belajar siswa.

Secara individual, bahwa terdapat kaitan antara self-confidence dengan hasil belajar, yaitu self-confidence sangat tinggi atau tinggi berdampak pada hasil belajar yang sangat tinggi atau tinggi pula, demikian juga sebaliknya. Pada penelitian ini, terdapat temuan-temuan yang tidak sesuai dengan penelitian sebelumya, temuan tersebut berupa adanya siswa yang mendapatkan self-confidence sangat tinggi atau tinggi tetapi mendapatkan hasil belajar kategori sedang bahkan rendah. Setelah dilakukan wawancara terhadap siswa, terdapat beberapa alasan yang dikemukakan, diantaranya, kondisi kelas yang tidak nyaman sehingga membuat sebagian siswa merasa terganggu dan merusak fokus pada saat pembelajaran, kurangnya fokus pada saat proses pembelajaran juga mengakibatkan ketidakpahaman siswa terhadap materi saat itu, sehingga siswa bingung dalam penggunaan rumus-rumus yang seharusnya digunakan, faktor lain yang mempengaruhi yaitu kurangnya belajar pada saat sebelum melakukan ujian, dikarenakan siswa sudah merasa paham dengan materi yang telah dijelaskan, ternyata pada saat proses ujian siswa melakukan kesalahan. Kelelahan juga merupakan salah satu faktor menurunya hasil belajar siswa, sehingga pikiran siswa tidak fokus terhadap materi pada saat itu.

Secara klasikal self-confidence dan hasil belajar siswa pada pembelajaran berbasis UKBM memiliki hubungan yang positif. Hal ini juga sejalan dengan teori sebelumnya yang menjelaskan bahwa semakin tinggi tingkat self-confidence yang dimiliki siswa, maka akan semakin baik juga hasil belajar yang akan didapatkan. Dalam penelitian ini juga dapat dilihat bahwa terdapat hubungan antara selfconfidence siswa dengan hasil belajar.

Dampak Pembelajaran matematika berbasis UKBM bukan hanya sekedar pembelajaran yang mengedepankan kemampuan tetapi juga mengedepankan rasa self confidence yang harus tertanam pada diri siswa. Penelitian ini menunjukkan bahwa self confidence sangatlah penting dimiliki bagi setiap siswa dalam proses pembelajaran berbasis UKBM, karena pembelajaran matematika berbasis UKBM lebih mengedepankan rasa self confidence. Dengan rasa self confidence itulah siswa dapat lebih mempercayai kemampuanya sendiri serta yakin bahwa siswa dapat melakukan proses pembelajaran matematika berbasis UKBM dengan baik.

\section{KESIMPULAN DAN SARAN}

Berdasarkan paparan di atas maka self-confidence siswa SMA dalam pembelajaran matematika berbasis UKBM tergolong tinggi, dan hasil belajarnya juga tinggi. Secara individual dan secara klasikal, ada hubungan antara selfconfidence dan hasil belajar. Ada kecenderungan bahwa self-confidence tinggi bersesuaian dengan hasil belajarnya yang juga tinggi. Atas dasar itulah maka perlu disarankan bahwa pembelajaran matematika berbasis UKBM perlu dikembangkan dan diterapkan di berbagai jenis dan jenjang sekolah

\section{DAFTAR PUSTAKA}

Andayani, M., \& Amir, Z. (2019). Membangun Self-Confidence Siswa melalui Pembelajaran Matematika. Desimal: Jurnal Matematika, 2(2), 147-153. https://doi.org/10.24042/djm.v2i2.427 9. 
DOI: https://doi.org/10.24127/ajpm.v9i2.2800

Apollo. (2018). Hubungan antara Kepercayaan Diri dengan Prestasi Belajar Siswa. Jurnal Psikologi Tabularasa, 3(1).

Apriliarini, D. (2015). Peningkatan Percaya Diri Melalui Model Pembelajaran Kooperatif Tipe Thingking Pair Share Pada Pembelajaran IPS Siswa Kelas V SD Negeri Serang Kulon Progo. Jurnal Pendidikan Guru Sekolah Dasar, 1(30), 77-87.

Astuti, E. P., Kurniasih, N., \& Nugraheni, P. (2016). Pengaruh Readiness dan Self-Confidence terhadap Penguasaan Geometri Transformasi Mahasiswa Pendidikan Matematika Universitas Muhammadiyah Purworejo. Beta Jurnal Tadris Matematika, 9(1), 7588.

https://doi.org/10.20414/betajtm.v9i1. 4

Direktorat Pembinaan Sekolah Menengah Atas. (2017). Panduan Pengembangan Unit Kegiatan Belajar Mndiri.

Effendi, M. M. (2019). Analysis of Humanist Education on VHS Mathematics Curriculum. Advances in Social Science, Education and Humanities Research, 349(Iccd), 339341. https://doi.org/10.2991/incomed17.2018.1

Hendriana, H. (2014). Membangun Kepercayaan Diri Siswa Melalui Pembelajaran Matematika Humanis. Jurnal Pengajaran Matematika Dan Ilmu Pengetahuan Alam, 19(1), 5260.

https://doi.org/10.18269/jpmipa.v19i1. 424

Indonesia, R. (2013). Peraturan Pemerintah Nomor 32 Tahun 2013 tentang Perubahan atas Peraturan Pemerintah Nomor 19 Tahun 2005 tentang Standar Nasional Pendidikan. Jakarta.

Irwantha, M. D., Ayu Putu Sriasih, S., \& Nurjaya, I. G. (2017). Penggunaan unit kegiatan belajar mandiri oleh Guru dalam Pembelajaran Bahasa Indonesia di kelas $X$ Mipa 2 Sma Negeri Bali Mandara. E-Journal
Jurusan Pendidikan Bahasa Dan Sastra Indonesia, 7(2), 12.

Isroila, A., Munawaroh, F., Rosidi, I., \& Muharrami, L. K. (2018). Pengaruh Self Confidence Terhadap Pemahaman Konsep Siswa Melalui Penerapan Model Problem Based Learning. Jurnal of Natural Science Education Research, 1(1), 1-8. Retrieved from https://journal.trunojoyo.ac.id/nser/arti cle/view/4151

Komari Pratiwi, N. (2015). Pengaruh Tingkat Pendidikan, Perhatian Orang tua, dan Minat Belajar Siswa Terhadap Prestasi Belajar Bahasa Indonesia Siswa SMK Kesehatan di Kota Tangerang. Jurnal Pujangga, Vol. 1(No 2), 75-105.

Majid, M. I., \& Linuwih, S. (2019). Pengembangan Unit Kegiatan Belajar Mandiri (UKBM) Materi Usaha dan Energi Berbasis Pembelajaran Kontekstual untuk Meningkatkan Pemahaman Konsep Siswa. UPEJ: Unnes Physics Education Journal, 8(3), 228-238.

Novitasari, D. (2016). Pengaruh Penggunaan Multimedia Interaktif Terhadap Kemampuan Pemahaman Konsep Matematis Siswa. FIBONACCI: Jurnal Pendidikan Matematika Dan Matematika, 2(2), 8. https://doi.org/10.24853/fbc.2.2.8-18

Nurafni, A., \& Pujiastuti, H. (2019). Analisis Kemampuan Koneksi Matematis ditinjau dari Self Confidence Siswa: Studi Kasus Di SMKN 4 Pandeglang. ANARGYA: Jurnal Ilmiah Pendidikan Matematika, 2(1), 28-33.

Nurkholifah, S., Toheri, \& Winarso, W. (2018). Hubungan Antara Self Confidence Dengan Kemampuan Berpikir Kritis Siswa Dalam Pembelajaran Matematika. Edumatica, 08(01), 58-66. Retrieved from

https://www.researchgate.net/publicati on/325094014_HUBUNGAN_ANTA RA_SELF_CONFIDENCE_DENGA N_KEMAMPUAN_BERPIKIR_KRI 
DOI: https://doi.org/10.24127/ajpm.v9i2.2800

TIS_SISWA_DALAM_PEMBELAJ ARAN_MATEMATIKA

Ratulangi, T., \& Arsyad, N. (2016). Analisis Kemampuan Guru Mengelola Pembelajaran Matematik Menurut Kurikulum 2013 di SD Negeri 1 Sopai Kabupaten Toraja Utara. JURNAL DAYA MATEMATIS, 4(1), 13-20.

Relita, D. T., \& Regina, F. (2015). Hubungan Antara Rasa Percaya Diri Dengan Hasil Belajar Pada Mata Pelajaran Ekonomi Siswa Kelas XI S ekolah Menengah Atas KaryaSekadau Tahun Pelajaran 2014/2015. Jurnal Profit, 2(2), 122-130.

Santosa, P. M. (2018). Peningkatan Percaya Diri Siswa Menggunakan Metode Bermain. Jurnal Pendidikan Guru Sekolah Dasar, 38(7), 3.745-3.754.

Setiyorini, E. (2016). Factors Relating Concentration Level of the First Semester Nursing Students of STIKes Patria Husada Blitar. Jurnal Ners Dan Kebidanan (Journal of Ners and Midwifery), 3(3), 247-252. https://doi.org/10.26699/jnk.v3i3.art.p 247-252

Setyani, M. R., \& Ismah. (2018). Analisis Tingkat Konsentrasi Belajar Siswa Dalam Proses Pembelajaran Matematika Ditinjau Dari Hasil Belajar. Jurnal Pendidikan Matematika, 01, 73-84.

Syam, A., \& Amri. (2017). Pengaruh Kepercayaan Diri (self confidence) Berbasis Kaderisasi Terhadap Prestasi Belajar Mahasiswa (Studi Kasus di Program Studi Pendidikan Biologi Fakultas Keguruan dan Ilmu Pendidikan Unoversitas Muhammadiyah Pare-Pare). Jurnal Biotek, 5(1), 87-102. Retrieved from http://journal.uinalauddin.ac.id/index.php/biotek/article /viewFile/3448/3243

Vandini, I. (2016). Peran Kepercayaan Diri terhadap Prestasi Belajar Matematika Siswa. Formatif: Jurnal Ilmiah Pendidikan MIPA, 5(3), 210-219. https://doi.org/10.30998/formatif.v5i3. 646
Wiharni, E., Amin, M., \& Lestari, S. R. (2018). UKBM in Enhancing Students , Scientific Literacy Skills on Kingdom Plantae Materials. Jurnal Pendidikan Sains, 6(3), 67-71.

Wulandari, \& Sinambela, N. (2017). Hubungan Kepercayaan Diri (SelfConfidence) Dengan Kemampuan Pemecahan Masalah Matematika Siswa Dengan Menggunakan Model Problem Basedlearning Di Man Kisaran. Inspiratif : Jurnal Pendidikan Matematika, $3(2)$. https://doi.org/10.24114/jpmi.v3i2.89 92 